\title{
Adoption of Flipped Classrooms in K-12 Education in Developing Countries: Challenges and Obstacles
}

\author{
https://doi.org/10.3991/ijet.v12i10.7308 \\ Abubaker Kashada $\left.{ }^{\varpi}\right)$, Hongguang Li, Chong Su \\ Beijing University of Chemical Technology, Beijing, China \\ $2012420020 @$ mail.buct.edu.cn
}

\begin{abstract}
The popularity of flipped classrooms has been growing worldwide and developing nations have not been left behind. It is a model that reschedules time spent in an outside classroom and its main strength is the shifting of learning ownership from the teacher to the student. This study investigates the challenges and obstacles of adopting flipped classrooms in K-12 education in developing countries. The methodology used to identify the challenges facing flipped classroom adoption in developing countries was based on the three research questions. With this in mind, the study reviewed publications on the topic after searching them in the major databases. The results showed a positive relationship between adoptions of flipped classrooms to student achievement. However, students' attitude had a positive, neutral and negative relationship to the adoption of flipped classrooms. Additionally, a set of challenges were identified in this study.
\end{abstract}

Keywords-Emerging Technologies, Educational technology, electronic learning, flipped classrooms, K-12 education

\section{Introduction and background}

Flipped classrooms in education are not describable as a new idea although the idea has been gaining plenty of popularity in math classrooms, middle schools and high schools [1]. A flipped classroom is a model of learning that readjusts and reschedules time spent both in and out of the classroom that enhances the shifting of ownership of learning to the students undertaking the studies from the teachers and educators [1]. Before attending class, students watch lecture videos, engaging their colleagues in the undertaking of project-based learning objectives, listening to podcasts and other remote instruction forms. After the out of class activities, the students are able to participate in attempts to solve challenges or problems designed to enhance content understanding. There are various benefits of making use of flipped classrooms including increased student engagement, an undertaking of meaningful homework and enhanced learning.

There are various advantages of making use of flipped instructor that include the teacher acting as an instructional guide as opposed to information dispenser. Additionally, the teacher has more time to teach the more difficult topics and deliver dif- 
ferentiated instruction [1]. The flipped classroom model ensures that the teacher is flexible in adapting strategies that suit the students' learning needs to enhance learning. Even as the teacher and student enjoy the benefits of the model, there is a major disadvantage of professional development. The teacher needs to have plenty of experience on the subject matter and pedagogy as it is a bit chaotic and for success, the teacher must have an experience of about 7 years.

There is the estimation that flipping of a particular classroom leads to about 2 weeks of content coverage compared to traditional methods. Student performance is the greatest benefit of the model as a result of all the strengths of the model. Most critics of the teaching method cite challenges for students in developing countries that include limited internet access, poor information communication technology ICT infrastructure, lack or no government support, lack of computer ownership, poor or no ICT infrastructure, informal learning, lack of professional development and resistance to change. More so, the teachers' workload increases as they create content [2].

There are four requirements aiding the success of flipped requirements:

1. Flexible environment - unlike traditional classrooms that are non-conducive to learning, flipped classrooms require students to work in groups and in very flexible environments, students are able to choose where and when to learn and teachers and educators accept this circumstance [1].

2. A change in the learning culture - traditional models identify the teachers as the solitary knowledge holders, unlike flipped classrooms that identify the students through direct learning [1]. In an ideal world, flipped educators should help the students learn topics in greater depth by the use of pedagogies that are studentcentered [3].

3. Intentional content - educators' main objective is content an instructional delivery mode selection and the educator must establish concept suitability to the mode of delivery. The educator must be flexible enough to adjust from traditional instructional methods [1].

4. Professional educators - for success in the flipped classroom model, experienced teachers are best suited as the teachers must capitalize on the learning opportunities existing and must observe the students keenly to guide them [3].

There are plenty of conclusions from the previous studies on flipped classrooms but most of these researches are limited in their findings. Some research limited their reviews to higher education while others were limited to post-secondary education subject disciplines. At the time of writing this article, there has been the publishing of only one literature review study with a special focus on K-12 education's flipped classroom [2][4]. Thus, a further systematic review is needed to investigate K-12 flipped classrooms' implementation.

The current review examines (a) effects of flipped classrooms in K-12 education, (b) flipped classroom activities, (c) students' attitude towards flipped classroom, (d) challenges of implementing flipped classrooms and (e) possible solutions to the challenges. 


\subsection{Research Questions}

The study was guided by the following questions:

1. What effect does flipped classroom have on students' performance and attitude?

2. What are the main challenges experienced by students using flipped classroom in developing countries?

3. How can we address the possible challenges?

\section{Methodology}

Few publications have been made reviewing the use of flipped classroom in learning. Lo and Hew [5] in their review of flipped classroom usage in education concluded that there was a positive and neutral relationship between flipped classroom and student performance. Another study by Bishop and Verleger [6] revealed that there is a positive relationship between flipped classroom and design acceptance. Due to the scarcity of publications, the study took into consideration 10 articles all published on and after 2013. To an attempt to ensure that all relevant publications were located, there was a search on the major databases.

There was the use of keywords that included "flipped classroom" or "flipped classroom" and "challenges" or "flipped classroom" and "solutions" or "flipped classroom" and "trends" or "flipped classroom" and "student performance and student appraisal". The search yielded 32 results following then removal of all duplicates. After article location, there was the organization and tabulation of the articles according to context, which was the discipline and type including practical an editorial. A total of 10 publications were useful in the final synthesis. Fig1. shows the flowchart of article selection process.

\section{$3 \quad$ Analysis and discussion}

Most of the studies were done in the United States but there were others from nations such as Hong Kong while the articles were widespread in terms of discipline including Engineering and Mathematics. Not all studies made a complete profile of their student participant's grade level and age. Nevertheless, most flipped classrooms begin from grades 9 .

\subsection{Effect of flipped classrooms to students' performance and attitude}

There was a variety of learning activities used including text materials, note-taking, online discussions and note-taking, individual practices, small-group activities, student presentation, a short lecture, quizzes, brief review, and self-evaluation. All these activities were in addition to the use of videos. Table 1 shows a summary of flipped classroom activities 


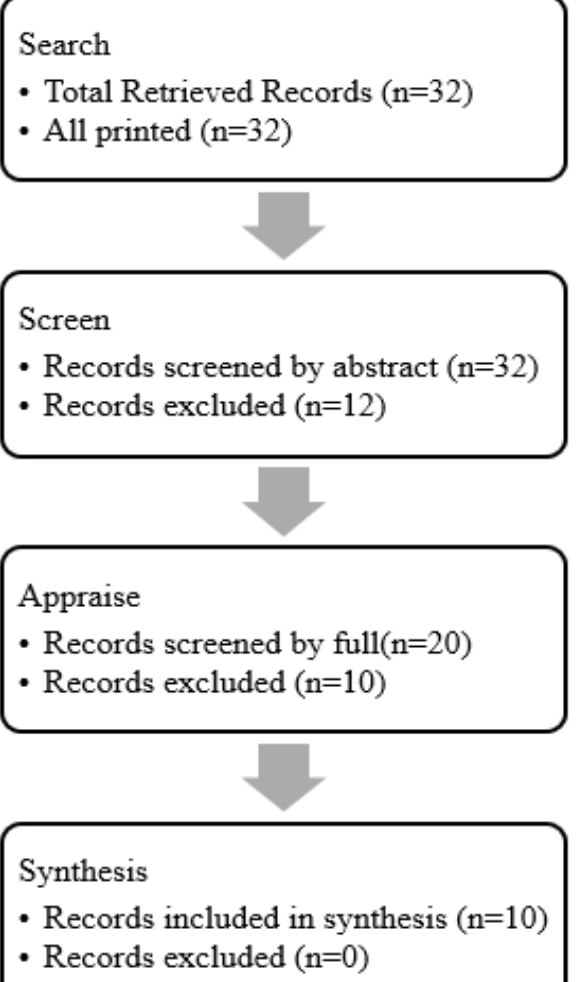

Fig. 1. Flowchart showing article selection process.

Table 1. Summary of flipped classroom activities

\begin{tabular}{|l|l|l|}
\hline \multicolumn{1}{|c|}{ Pre-class activities } & \multicolumn{1}{c|}{ In-class activities } & \multicolumn{1}{c|}{ After-class activities } \\
\hline - Online discussion & - Short lecture & - Self-evaluation \\
- Online exercises & - Quizzes & \\
- Note making & - Brief review & \\
- Text materials & - Student presentation & \\
& - Group activities & \\
& - Individual practices & \\
\hline
\end{tabular}

All these activities had a positive or at least neutral relationship to the students' performance. In the determination of the effect of flipped classroom, there was the use of quasi-experimental that involves the comparison of studies with one group undertaking a traditional classroom and another flipped classroom. A word of caution to all those that are going to view our findings as there are some limitations to the study. First, not all studies made use of pre-treatment assessment in the evaluation of initial equivalence among groups leading to uncertainty in the comparability of assessment groups, which was a hindrance for further analysis. Second, the interventions duration was short. Some studies acknowledged that students' performance will receive a 
boost in the short-run due to the introduction of new technology while other studies concluded that some educators will spend more time and effort in the flipped groups. Third, there was the use of little empirical studies and more are needed.

In the determination of the students' attitude on the use of flipped classroom model, there was the examination of self-reported data collected through interviews and surveys. Additionally, there was the use of educators' reflections and compiling of observations in reviewed publications. Lo and Hew [5] state that most if not all students are satisfied with the use of flipped classroom. The high satisfaction by the students is attributable to three advantages of flipped courses:

1. The use of video lectures pre-class was a helpful activity as the student prepared for that class. Moreover, video lectures were easier to understand and fun as compared to reading other materials. The ability to pause, rewind and making reviews of the lecture had a favorable perception of the students to the flipped classroom as the students made notes at their own pace and reviews helped the students' gain a better understanding. According to Ankeny and Krause [7], students were able to access learning materials all the time, providing flexibility for the learners and creation of time to try and solve complex problems.

2. Flipped classroom enhanced student to student and student to educator interactions during class meetings. There was the promotion of students' interactions during inclass activities that include group discussions while promoting the clarification of learning goals. In turn, there was the development of teamwork skills that are important in extracurricular activities and career activities. Also, the teacher would help low achievers as the students are able to get the teacher's attention, which translates to better performance.

3. All knowledge acquired by the students was utilized in problem-solving scenarios while engaging in other discussions. The use of flipped classroom approach promoted efficiency and the students enjoyed learning.

Other benefits from the use of flipped classrooms include the use of face-to-face lecture time in solving complex exercises as the students interact with their peers and with the educator. Students enjoy working with their peers whenever an educator is available to help the group [8]. Additionally, students are able to acquire professional skills that are in line with today's competitive market that is changing on a daily basis. More so, students come to class better prepared that promotes student engagement [9].

Despite the positive findings of flipped classroom towards student satisfaction, some studies had a contrary finding. DeSantis, Van Curen, Putsch and Metzger [10] in their study indicated that there was a neutral relationship between flipped classroom and students' performance when compared to traditionally taught lessons. There was a negative relationship between students' attitude and flipped classroom engagement unlike students taking part in traditional lessons that reported higher satisfaction [10]. 


\subsection{Challenges of using Flipped Classrooms in developing countries}

Educators experience a heavy workload pre-and during class as the educator must input their time and front-end investment while during class, the educator must serve a number of students that ask for assistance. On the other hand, the new approach may be challenging to the students due to technical issues and uninteresting online materials with long online videos leading to the lack of interest.

Resistance to technology and change may be another challenge. Resistance may be in many forms but most reports talk of "status quo comfort". Most teachers and principals describe technological experimentation as outside their job description scope [11]. Furthermore, whenever students faced a new learning model, the students were overwhelmed as they were required to actively take part in the learning process.

There is the creation of a digital divide as one of the prominent issues in the adoption of flipped classrooms is the students' access to the internet and a computer so that they can view a lecture [12]. This is a tough ask from students in the developing world and even those in low-income districts as they already have limited resources. With resources limitation, most students are unable to complete the tasks in time or after normal schooling hours. Additionally, there are many students who miss the lectures and quizzes involuntary as they do not learn from the quizzes and lectures.

At the institutional level, there must be the redesigning of the courses, which calls for a financial investment by both the government and the institutions among other stakeholders. The investment includes infrastructure and hiring of more educators with the required skills. To rationalize and justify time and money investments in flipped classrooms, the approach should be in use for a number of years in different courses. There must be the encouragement of the educators to attempt and develop flipped classrooms. However, even with the encouragement, there must be the investment in ICT infrastructure by the government and educational institutions.

Educators do not possess technological self-efficacy; the belief by an individual in his/her own ability to use technology and in this case computers to ensure that he/she accomplishes a task. Flipped classrooms approach relies on technology and most institutions have not been able to learn their content with the suitable technological options available. Thus, teachers do not possess essential experiences that allow them to reach their content with the technologies [13].

\subsection{Possible Solutions}

There are various solutions that can be undertaken and include the following:

- There should be a support network for students with limited technology resources not all students have the resources to access the internet or even afford a personal computer. With little or no support, some learners may lose the opportunity to study in flipped classrooms. Teachers must consider the socio-economic status of students while making sure there is IT support.

- Enriching the teachers' knowledge on the approach - teachers must embrace the essential value of the new model and explore innovative ways to use the model in class time. Institutes should create opportunities and avenues for teachers to share 
their experiences on the implementation process and receive feedback from professionals and colleagues. Institutions should strengthen their teacher professional development on the approach.

- Retaining the workload - both teachers and K-12 students complain of pre-class workload. Teachers should estimate the time required to complete the homework given. More so, videos should be a maximum of 20 minutes to ensure that students' concentration is maintained and the students are able to study at their own pace. Also, the teachers should design the learning activities that are simple to understand. Hence, both the teacher and student will not become frustrated by the extra workload.

- Open communication platform between all stakeholders in the education sector to ensure that the government provides the infrastructure required, there should be the communication between institutions, students and government on the useful technology so that there is the development of the infrastructure.

- Online discussions - students taking part in a flipped classroom environment is not in a position to interrupt the teacher to ask questions or to seek clarification on the topic. Nevertheless, the teacher can create an online platform that allows the discussion is extended and comprehensive outside the classroom.

- Progressive preparation of flipped learning materials - as teachers seek experience useful in the use of technology in learning, they must ensure that they manage their workload. Thus, the teachers should start small and continue at a reasonable pace. Teachers should experiment in small ways so that they can gain the experience needed. Additionally, teachers can flip their courses in teams to ensure that they help each other.

- Student monitoring and motivation - it is difficult for the teachers to know whether the students have previewed the videos. The teacher should ensure there are follow-up questions and quizzes to help the students preview the materials. The use of the learning management system (LMS) helps monitor and record student data. In addition to the system, there can be the use of gamification, which allows the students to gain digital game elements that include leaderboard, badges, and points and it has a positive relationship to student motivation. Through gamification, students spend more time online and even attempt to tackle the more difficult tasks.

- Institutional support - success of the flipped classroom model is dependent on the support and investment by institutions in terms of Information Technology (IT) resources. Teachers may experience issues that include poor video production and they require support from IT staff. Additionally, institutions may allocate additional manpower to enhance the implementation of flipped classrooms, which will promote the development of materials collaboratively.

\section{Conclusion}

The primary objective of engaging technology in a learning environment is to provide a personal and important learning experience to all students undertaking certain courses. The systematic review of flipped classroom in this study is timely as the 
approach is gaining popularity not only in developed nations but also in developing countries. The review of the 10 publications in the study was framed around three research questions. First, the study found that there exists a positive relationship between flipped classroom model adoption to students' performance and a positive and neutral relationship between flipped classroom adoption models to students' attitude. Second, challenges highlighted included lack of infrastructure, poor internet connection, lack of computers for personal use, lack of investment, resistance to change and increased teachers' workload. Third, there are recommendations on the possible solutions to the problems.

It is clear that the government and all other stakeholders must intervene in the provision of ICT infrastructure to ensure that all students are in a position to participate in flipped classrooms. For students, a model is a student-centered approach with emphasis on interaction and engagement while using online materials. The approach provides the students with an opportunity to learn anytime and anywhere even when outside the classroom at their own pace. Students are in a position to use study strategies that see fit. In developing countries, students can be in a position to undertake high-demand courses as there is no restriction on the size of the classroom. Not only is the approach useful in the content delivery but also useful in skill development such as communication, collaborative problem-solving team building, and critical thinking skills. There is a need to ensure that computer and internet services are cheap and available to all people globally as with the incorporation of technology in education, there is a chance to grow accessibility to education for all those living in developing nations.

\section{$5 \quad$ Implications of the study}

The primary aim of the study was to identify challenges faced by developing nations in the adoption and implementation of the flipped classroom model in their educational institutions, which has been done through the seeking of responses to the three research questions. There was the determination of the challenges that both the sector, teachers and students face. After the determination, there are some implications for practice. First, to determine the challenges, there was the reviewing of literature by other publishers. Thus, the study will provide a considerable amount of empirical data on the challenges that students and teachers in developing countries face. The information is important as there are very few studies done on flipped classrooms and only a handful of the challenges faced in the implementation of flipped classrooms. Therefore, this study is timely.

Second, due to the positive relationship between adoption of flipped classrooms and student's performance despite the many challenges, the study's finding suggest that the model should be adopted worldwide as it will help all those unable to attend school to have an opportunity. Even as the need to adopt the model is emphasized, there should be the continuous monitoring of ICT infrastructure by the government and other stakeholders. Education stakeholders should reflect on the sector through the following essential questions: 
Paper-Adoption of Flipped Classrooms in K-12 Education in Developing Countries: Challenges and ...

- How well do the present ICT infrastructure fit current and future trends in education?

- What measures can be undertaken to fix the issue both short-term and long-term?

- What training can teachers undergo to ensure they are able to make use of technology in education?

What will be the effect of investing in the adoption of technology in education and are the expected effects in line with the overall goals both at national, institutional and personal levels?

\section{$6 \quad$ Research limitations}

The study has some limitations that include the small number of publications to review as most articles highlighting flipped classrooms issues were not relevant to the study. The study did not incorporate many publications on issues facing flipped classrooms in the developing countries as there are very few publications and only on the study on a university of South Africa was used. Furthermore, there were mixed reactions in the relationship between the use of flipped classrooms to students' attitude as different studies have different results as there were those concluding of a positive relationship, other negative relationship while other negative relationship.

\section{$7 \quad$ Recommendations and future work}

Future studies will include the application and measurement of the effectiveness of the flipped classroom model when compared to the traditional course. The measurement of effectiveness will cover learning outcomes and student engagement. There will be the choosing of institutions offering K-12 education so that there is the conducting of a pilot survey. There will be the conversion of a large class into flipped classroom. There will be a survey with the use of questionnaires to determine the challenges of both students and teachers. There will be efforts to contact a government representative who will help in the determination of efforts undertaken by the government in the promotion of education through technology and specifically flipped classrooms. There will be the use of a pre-test in the comparison study to eliminate the assumption both the traditional group and the flipped classroom group are similar. All these efforts will help address some limitations of previous studies.

Conflict of interest: The authors declare that they have no conflict of interest. 


\section{References}

[1] Reiser, R. A. (2017). "Eight Trends Affecting the Field of Instructional Design and Technology: Opportunities and Challenges". In Learning and Knowledge Analytics in Open Education (pp. 139-147), Springer International Publishing. https://doi.org/10.1007/978-3319-38956-1 11

[2] Lai, C. L. \& Hwang, G. J. (2016). “A self-regulated flipped classroom approach to improving students' learning performance in a mathematics course". Computers \& Education, 100, 126-140. https://doi.org/10.1016/j.compedu.2016.05.006

[3] Beynon, M. (2006, July). "Towards technology for learning in a developing world". In Technology for Education in Developing Countries, 2006. Fourth IEEE International Workshop on (pp. 88-92), IEEE. https://doi.org/10.1109/TEDC.2006.32

[4] Zengin, Y. (2017). "Investigating the Use of the Khan Academy and Mathematics Software with a Flipped Classroom Approach in Mathematics Teaching". Journal of Educational Technology \& Society, 20(2), 89-100.

[5] Lo, C. K. \& Hew, K. F. (2017). "A critical review of flipped classroom challenges in K-12 education: possible solutions and recommendations for future research". Research and Practice in Technology Enhanced Learning, 12(1), 4. https://doi.org/10.1186/s41039-0160044-2

[6] Bishop, J. \& Verleger, M. (2013, October). "Testing the flipped classroom with modeleliciting activities and video lectures in a mid-level undergraduate engineering course". In Frontiers in Education Conference, 2013 IEEE (pp. 161-163), IEEE. https://doi.org/10.1109/FIE.2013.6684807

[7] Ankeny, C. J. \& Krause, S. J. (2014). "Flipped biomedical engineering classroom using pencasts and muddiest point web-enabled tools". In 121st ASEE Annual Conference and Exposition: 360 Degrees of Engineering Education, American Society for Engineering Education.

[8] Bates, J. E., Almekdash, H. \& Gilchrest-Dunnam, M. J. (2017). "The Flipped Classroom: A Brief, Brief History". In The Flipped College Classroom (pp. 3-10), Springer International Publishing. https://doi.org/10.1007/978-3-319-41855-1 1

[9] Zhang, Y., Dang, Y. \& Amer, B. (2016). "A Large-Scale Blended and Flipped Class: Class Design and Investigation of Factors Influencing Students' Intention to Learn". IEEE Transactions on Education, 59(4), 263-273. https://doi.org/10.1109/TE.2016.2535205

[10] Desantis, J., Van Curen, R., Putsch, J. \& MetzgeR, J. (2015). "Do students learn more from a flip? An exploration of the efficacy of flipped and traditional lessons". Journal of Interactive Learning Research, 26(1), 39-63.

[11] Bowers, J. \& Kumar, P. (2017). "Students' perceptions of teaching and social presence: A comparative analysis of face-to-face and online learning environments". In Blended Learning: Concepts, Methodologies, Tools, and Applications (pp. 1532-1550), IGI Global. https://doi.org/10.4018/978-1-5225-0783-3.ch073

[12] Maneeratana, K., Singhanart, T. \& Singhatanadgid, P. (2016, December). “A preliminary study on the utilization and effectiveness of a flipped classroom in Thailand". In Teaching, Assessment, and Learning for Engineering (TALE), 2016 IEEE International Conference on (pp. 345-352), IEEE. https://doi.org/10.1109/TALE.2016.7851819

[13] Mapotse, T. A. "Development of a Technology Education Cascading Theory through community engagement site-based support". International Journal of Technology and Design Education, 1-15. https://doi.org/10.1007/s10798-017-9411-6 


\section{$9 \quad$ Authors}

Abubaker Kashada was born in Zawia, Libya in 1966. He received the Master's degree in Information and Communications Technology for Engineering ICTE in 2003 from Coventry University, UK. At present, he is a postgraduate student of information science and technology at the College of Information Science and Technology, Beijing University of Chemical Technology. His current research interests include IT infrastructure, Information and Communication Technology, Internet Technologies, Educational Technology.(2012420020@mail.buct.edu.cn).

Hongguang Li was born in Liaoning Province, P. R. China in 1963. He received the Ph. D. degree in East China University of Science and Technology in 2004. At present, he is professor at the College of Information Science and Technology, Beijing University of Chemical Technology. His research interests are Modeling, control and optimization of chemical process as well as computer based intelligent control for industrial. (lihg@mail.buct.edu.cn).

Chong Su was born in Tianjin, P. R. China in 1983. He is the full time Ph. D. candidate and Lecturer at the College of Information Science and Technology, Beijing University of Chemical Technology. His research interests are intelligent applications, affect computing and human-computer interaction. (suchong@mail.buct.edu.cn).

Article submitted 17 June 2017. Published as resubmitted by the authors 01 August 2017. 